\title{
Vitamin supplement use and breast cancer in a North Carolina population
}

\author{
Patricia G Moorman ${ }^{1,2, *}$, Mary F Ricciuti ${ }^{1}$, Robert C Millikan ${ }^{3}$ and Beth Newman ${ }^{4}$ \\ 'Department of Epidemiology and Public Health, Yale University School of Medicine, New Haven, CT, USA: \\ ${ }^{2}$ Current affiliation: Cancer Prevention, Detection, and Control Research Program, Room 239, Hanes House, Trent \\ Drive, Box 2949, Duke University Medical Center, Durham, NC 27710, USA: ${ }^{3}$ Department of Epidemiology and \\ Lineberger Comprehensive Cancer Center, University of North Carolina, Chapel Hill, NC, USA: ${ }^{4}$ Queensland \\ University of Technology School of Public Health, Kelvin Grove, Queensland, Australia
}

Submitted 14 September 2000: Accepted 12 December 2000

\begin{abstract}
Objective: Laboratory data suggest that several different vitamins may inhibit the growth of mammary cancers, however epidemiologic data on the relationship between vitamin supplement use and breast cancer are inconsistent. We examined the association between self-reported vitamin supplement use and breast cancer among black women and white women.

Design and setting: The data came from a population-based, case-control study conducted in North Carolina between 1993 and 1996. Logistic regression models were used to calculate adjusted odds ratios (ORs) for breast cancer associated with the use of multivitamins or individual vitamin supplements.

Subjects: Eligible cases were aged 20 to 74 , and approximately $40 \%$ of the study population were black women. The analyses included 861 cases and 790 controls. Results: Among all women, there was little evidence for an association between any vitamin supplement and breast cancer. Modest inverse associations were observed among white women for use of multivitamins ( $\mathrm{OR}=0.81,95 \%$ confidence interval (CI): 0.59-1.12), vitamin C $(\mathrm{OR}=0.78,95 \% \mathrm{CI}: 0.54-1.14)$ and vitamin $\mathrm{E}(\mathrm{OR}=$ 0.75, 95\% CI: $0.49-1.13)$. There was no evidence that vitamin supplements reduced the risk of breast cancer among black women.

Conclusions: This study provided very limited support for the hypothesis that vitamin supplements may reduce the risk of breast cancer. Although dietary factors are likely an important influence in breast cancer aetiology, reductions in risk are most likely to be achieved through dietary modification rather than through vitamin supplementation.
\end{abstract}

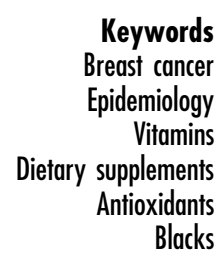

Several lines of evidence from laboratory studies suggest that antioxidant micronutrients may prevent mammary cancers ${ }^{1}$. Antioxidants, including vitamins A, C and E, trap free radicals and reactive oxygen molecules, preventing the cellular damage caused by these molecules when they react with proteins and nucleic acids ${ }^{2}$. Additional protective mechanisms may include regulation of cellular differentiation by vitamin $\mathrm{A}^{3}$, inhibition of the formation of carcinogenic nitrosamines by vitamins $\mathrm{C}$ and $\mathrm{E}^{4}$, and enhancement of the immune response by vitamins $C$ and $\mathrm{E}$ and $\beta$-carotene ${ }^{5}$. Animal feeding studies have shown that supplementation with vitamin $\mathrm{A}$, vitamin $\mathrm{E}$ or selenium reduces the formation of mammary tumours in rodents ${ }^{1}$.

Despite the laboratory evidence, epidemiological studies that have examined the relationship between breast cancer and vitamin consumption (either as components of dietary intake or as supplements) have produced inconsistent results ${ }^{6-8}$. Most investigations have not found significant inverse relationships between vitamin supplements and breast cancer, although a protective effect of vitamin $\mathrm{A}$ has been suggested in several studies ${ }^{9-11}$. Nonetheless, the association between vitamin supplements and cancer is of considerable public health interest. National surveys report that approximately $50 \%$ of the US population have used some type of vitamin supplement in the past year ${ }^{12}$, and annual sales of vitamin supplements in the United States total almost $\$ 5$ billion ${ }^{13}$. Increasingly, vitamin supplements are promoted in books, in advertisements and on the Internet for their antioxidant, anti-cancer properties.

The purpose of this study was to examine the 
relationship between vitamin supplement use and breast cancer risk in a population-based, case-control study of women in North Carolina. This study population, comprised of approximately $40 \%$ black women, also allowed an examination of potential racial differences in vitamin supplement use and their associations with breast cancer risk. Among the few studies of breast cancer risk factors among black women ${ }^{14-19}$, none has examined nutritional factors.

\section{Subjects and methods}

The Carolina Breast Cancer Study (CBCS), a populationbased, case-control study in central and eastern North Carolina, has been described in detail elsewhere ${ }^{20}$. Briefly, eligible cases were aged 20 to 74 , resided in the 24-county study area, and had a first diagnosis of invasive breast cancer between May 1993 and May 1996. Control women aged 20 to 64 were selected from North Carolina Division of Motor Vehicle lists of women with a driver's licence or identification card. Controls aged 65 to 74 were chosen from US Health Care Financing Administration lists. Black women and women under the age of 50 were over-sampled using a modification of randomised recruitment $^{21}$, with the goal of obtaining roughly equal numbers of black and white women, and women diagnosed before and after age 50 .

Women who agreed to participate completed a onehour, in-home interview with a registered nurse. Participants also were weighed and had body measurements taken. Among women who were located and eligible, $77 \%$ of cases and $68 \%$ of controls were interviewed ${ }^{22}$. Case response rates ranged from $83 \%$ for white women under age 50 to $68 \%$ for black women aged 50 or older. Control response rates ranged from $73 \%$ for white women under age 50 to $59 \%$ for black women aged 50 or older. The present analyses are based on the 1651 women (861 cases and 790 controls) who provided data on vitamin supplement use. Women of all races were included in the study, but white and black women comprised the vast majority of the population in the North Carolina study area. Women of other races, who represented only $1.6 \%$ of the study population, were included with white women in the race-specific analyses presented in this paper. Analyses also were performed excluding women whose reported race was neither white nor black, and the results were essentially identical to those in which women of other races were included with the white women. The study protocol was approved by the institutional review board of the University of North Carolina School of Medicine.

Data were obtained on established and hypothesised breast cancer risk factors including family history, menstrual and reproductive history, lifestyle characteristics, and hormone use. Participants were queried about their use of vitamin supplements, including multivitamins, vitamin A, vitamin $\mathrm{C}$, vitamin $\mathrm{E}, \boldsymbol{\beta}$-carotene and selenium, over the past five years. Information was obtained about the type of multivitamin or dose of individual vitamin supplements, duration of use in months, and frequency of use (days per week). A complete dietary history was not obtained from interviewed women; however, they were asked four questions in which they reported their usual weekly number of servings of fruit and vegetables during the winter and summer seasons over the past year, in order to allow a rough ranking of dietary intake of antioxidants.

Odds ratios (ORs) and 95\% confidence intervals (CIs) were calculated with logistic regression models, using the SAS GENMOD procedure (version 6.12; SAS Institute, Inc., Cary, NC), which allows incorporation of an offset term to account for the sampling fractions used in the randomised recruitment study design. Women who reported taking a vitamin supplement at least once a week for at least three months during the past five years were categorised as vitamin users. Covariates examined as potential confounders in multivariate models included: age (as 5-year intervals); age at menarche ( $\leq 11,12-13$ or $\geq 14$ years); age at first full-term pregnancy (nulliparous, $<20,20-29$ or $\geq 30$ years); lactation history (ever/never); menopausal status (pre-, peri- or post-menopausal); family history of breast cancer in a first-degree relative (yes/no); body mass index (BMI) quartiles (<24.00, 24.00-27.99, 28.0032.99 or $\geq 33.00 \mathrm{~kg} \mathrm{~m}^{-2}$, based on the distribution among controls); waist-to-hip ratio (WHR) quartiles $(<0.75$, $0.75-0.79,0.80-0.86$ or $\geq 0.87)$; education $(<12,12$ or $>12$ years); alcohol consumption (ever/never); smoking history (never, former, current); average of winter and summer weekly servings of fruit and vegetables (1-20, 21-30 or $>30$ ); and current fitness activities at least once a week (yes/no). A term for race (black/non-black) was included in those models not stratified by race.

\section{Results}

Descriptive characteristics of cases and controls, stratified by race, are presented in Table 1 . The associations between most risk factors and breast cancer were similar for black women and white women, although there were some exceptions. Among black women, high parity or younger age at birth of first child was not associated with decreased breast cancer risk. In addition, women who reported a low intake of fruit and vegetables and former smokers were at increased risk among black women, whereas there was no association with these factors among white women.

Table 2 depicts selected characteristics of vitamin users. White women were more likely to report vitamin supplement use than black women. Other characteristics associated with vitamin use included higher education, lower BMI and WHR, higher consumption of fruit and vegetables, and currently engaging in fitness activities. 
Table 1 Selected characteristics of breast cancer cases and controls, stratified by race, The Carolina Breast Cancer Study

\begin{tabular}{|c|c|c|c|c|c|c|c|c|}
\hline & \multicolumn{4}{|c|}{ Black women } & \multicolumn{4}{|c|}{ White women } \\
\hline & Cases $(n=335)$ & Controls $(n=332)$ & $\mathrm{OR}^{*}$ & $95 \% \mathrm{Cl}$ & Cases $(n=526)$ & Controls $(n=458)$ & $\mathrm{OR}^{*}$ & $95 \% \mathrm{Cl}$ \\
\hline \multicolumn{9}{|l|}{ Age (years) } \\
\hline $20-39$ & 61 & 45 & & & 97 & 55 & & \\
\hline $40-49$ & 114 & 126 & & & 233 & 181 & & \\
\hline $50-59$ & 61 & 69 & & & 71 & 81 & & \\
\hline $60-74$ & 99 & 92 & & & 125 & 141 & & \\
\hline \multicolumn{9}{|l|}{ Age at menarche } \\
\hline$<12$ & 92 & 80 & 1.00 & & 111 & 84 & 1.00 & \\
\hline $12-13$ & 168 & 155 & 0.90 & $(0.62-1.31)$ & 302 & 265 & 0.87 & $(0.62-1.22)$ \\
\hline$>13$ & 74 & 96 & 0.63 & $(0.41-0.96)$ & 113 & 107 & 0.80 & $(0.54-1.19)$ \\
\hline \multicolumn{9}{|l|}{ Parity } \\
\hline Nulliparous & 42 & 40 & 1.00 & & 91 & 49 & 1.00 & \\
\hline 1 & 62 & 61 & 1.01 & $(0.57-1.80)$ & 101 & 78 & 0.74 & $(0.47-1.18)$ \\
\hline 2 & 72 & 68 & 1.15 & $(0.66-2.00)$ & 195 & 185 & 0.63 & $(0.42-0.95)$ \\
\hline 3 or more & 159 & 163 & 1.06 & $(0.65-1.74)$ & 139 & 146 & 0.63 & $(0.41-0.98)$ \\
\hline \multicolumn{9}{|l|}{ Age at birth of first child } \\
\hline Nulliparous & 42 & 40 & 1.00 & & 91 & 49 & 1.00 & \\
\hline$<20$ & 139 & 24 & 1.09 & $(0.66-1.79)$ & 100 & 42 & 0.66 & $(0.42-1.04)$ \\
\hline $20-29$ & 132 & 127 & 1.10 & $(0.67-1.82)$ & 269 & 270 & 0.61 & $(0.41-0.91)$ \\
\hline$\geq 30$ & 19 & 139 & 0.82 & $(0.39-1.74)$ & 65 & 97 & 0.89 & $(0.53-1.52)$ \\
\hline \multicolumn{9}{|l|}{ Lactation history } \\
\hline No & 232 & 208 & 1.00 & & 340 & 268 & 1.00 & \\
\hline Yes & 103 & 124 & 0.70 & $(0.49-0.99)$ & 186 & 190 & 0.73 & $(0.56-0.95)$ \\
\hline \multicolumn{9}{|c|}{ First-degree family history of breast cancer } \\
\hline No & 282 & 283 & 1.00 & & 429 & 388 & 1.00 & \\
\hline Yes & 42 & 32 & 1.32 & $(0.80-2.15)$ & 84 & 57 & 1.43 & $(0.99-2.07)$ \\
\hline \multicolumn{9}{|l|}{ BMI $\left(\mathrm{kg} \mathrm{m}^{-2}\right)$} \\
\hline$\geq 33$ & 109 & 125 & 1.00 & & 54 & 60 & 1.00 & \\
\hline $28-32.99$ & 102 & 91 & 1.30 & $(0.88-1.91)$ & 80 & 94 & 0.97 & $(0.60-1.57)$ \\
\hline $24-27.99$ & 69 & 66 & 1.25 & $(0.81-1.91)$ & 158 & 129 & 1.44 & $(0.92-2.24)$ \\
\hline$<24$ & 43 & 39 & 1.18 & $(0.71-1.96)$ & 226 & 172 & 1.42 & $(0.93-2.17)$ \\
\hline \multicolumn{9}{|l|}{ Waist-to-hip ratio } \\
\hline$\geq 0.87$ & 117 & 101 & 1.00 & & 85 & 74 & 1.00 & \\
\hline $0.80-0.86$ & 93 & 91 & 0.88 & $(0.59-1.31)$ & 126 & 90 & 1.22 & $(0.80-1.86)$ \\
\hline $0.75-0.79$ & 57 & 62 & 0.73 & $(0.46-1.15)$ & 111 & 117 & 0.79 & $(0.52-1.20)$ \\
\hline$<0.75$ & 36 & 46 & 0.59 & $(0.35-1.00)$ & 153 & 148 & 0.77 & $(0.52-1.16)$ \\
\hline \multicolumn{9}{|l|}{ Educational level } \\
\hline$>$ High school & 137 & 136 & 1.00 & & 328 & 284 & 1.00 & \\
\hline High school graduate & 96 & 88 & 1.07 & $(0.73-1.56)$ & 142 & 117 & 0.96 & $(0.63-1.45)$ \\
\hline$<$ High school & 102 & 108 & 0.87 & $(0.60-1.29)$ & 56 & 57 & 1.12 & $(0.83-1.51)$ \\
\hline \multicolumn{9}{|l|}{ Smoking status } \\
\hline Never & 189 & 198 & 1.00 & & 255 & 225 & 1.00 & \\
\hline Former & 95 & 64 & 1.71 & $(1.17-2.49)$ & 172 & 141 & 1.08 & $(0.80-1.44)$ \\
\hline Current & 51 & 70 & 0.79 & $(0.52-1.20)$ & 99 & 92 & 0.95 & $(0.67-1.33)$ \\
\hline \multicolumn{9}{|l|}{ Alcohol consumption } \\
\hline Never & 111 & 103 & 1.00 & & 135 & 128 & 1.00 & \\
\hline Ever & 224 & 228 & 0.89 & $(0.67-1.19)$ & 391 & 330 & 1.01 & $(0.75-1.36)$ \\
\hline \multicolumn{9}{|c|}{ Weekly fruit and vegetable servings } \\
\hline$>30$ & 99 & 126 & 1.00 & & 162 & 181 & 1.00 & \\
\hline $21-30$ & 91 & 90 & 1.26 & $(0.85-1.87)$ & 164 & 127 & 1.12 & $(0.81-1.55)$ \\
\hline$<20$ & 143 & 114 & 1.51 & $(1.05-2.17)$ & 197 & 146 & 0.89 & $(0.65-1.21)$ \\
\hline
\end{tabular}

* OR=odds ratio, all ORs were adjusted for age.

There was no statistically significant association between smoking status and vitamin use.

The ORs associated with vitamin use among all women and white women and black women separately are shown in Table 3. Women who did not report use of any type of vitamin comprised the reference category. Among all women, there was little evidence for an inverse association between any vitamin supplement and 
Table 2 Comparison of characteristics of vitamin users and non-users, among control women, The Carolina Breast Cancer Study

\begin{tabular}{|c|c|c|c|}
\hline Characteristic & Vitamin users $(n=451)(\%)$ & Vitamin non-users $(n=339)(\%)$ & $\mathrm{OR}^{*}(95 \% \mathrm{Cl})$ \\
\hline \multicolumn{4}{|l|}{ Race } \\
\hline Black & 34.2 & 52.5 & $0.62(0.46-0.83)$ \\
\hline White & 65.9 & 47.5 & 1.00 \\
\hline \multicolumn{4}{|l|}{ Educational level } \\
\hline$<$ High school & 14.6 & 29.2 & $0.39(0.26-0.58)$ \\
\hline High school graduate & 25.9 & 26.0 & $0.80(0.56-1.13)$ \\
\hline$>$ High school & 59.4 & 44.8 & 1.00 \\
\hline \multicolumn{4}{|l|}{ BMI $\left(\mathrm{kg} \mathrm{m}^{-2}\right)$} \\
\hline$<24.00$ & 31.6 & 21.3 & $2.38(1.53-3.70)$ \\
\hline $24.00-27.99$ & 28.0 & 21.3 & $2.45(1.59-3.77)$ \\
\hline $28.00-32.99$ & 23.9 & 23.7 & $1.96(1.28-3.00)$ \\
\hline$\geq 33$ & 16.5 & 33.6 & 1.00 \\
\hline \multicolumn{4}{|l|}{ Waist-to-hip ratio } \\
\hline$<0.75$ & 29.6 & 22.7 & $1.90(1.22-2.97)$ \\
\hline $0.75-0.79$ & 28.6 & 19.2 & $2.45(1.57-3.83)$ \\
\hline $0.80-0.86$ & 23.6 & 26.5 & $1.52(0.99-2.33)$ \\
\hline$\geq 0.87$ & 18.3 & 31.6 & 1.00 \\
\hline \multicolumn{4}{|l|}{ Smoking status } \\
\hline Current smoker & 19.3 & 22.1 & $0.88(0.61-1.28)$ \\
\hline Ex-smoker & 27.7 & 23.6 & $1.09(0.77-1.55)$ \\
\hline Never smoker & 53.0 & 54.3 & 1.00 \\
\hline \multicolumn{4}{|c|}{ Fruit and vegetable intake (servings per week) } \\
\hline $1-20$ & 35.3 & 40.8 & $0.66(0.46-0.93)$ \\
\hline $21-30$ & 27.7 & 27.7 & $0.79(0.54-1.15)$ \\
\hline$>30$ & 37.1 & 31.6 & 1.00 \\
\hline \multicolumn{4}{|l|}{ Current fitness activities } \\
\hline Yes & 55.9 & 43.4 & $1.62(1.22-2.18)$ \\
\hline No & 44.1 & 56.6 & 1.00 \\
\hline
\end{tabular}

* OR for race adjusted for age, all other ORs adjusted for age and race.

breast cancer. ORs were only slightly below one for use of multivitamins, vitamin $\mathrm{C}$ and vitamin $\mathrm{E}$, and were modestly elevated for vitamin A, $\beta$-carotene and selenium.

Race-specific analyses suggested the possibility of different associations between vitamin use and breast cancer among black and white women. Among black women, there was no reduction in breast cancer risk associated with ever using any of the vitamin supplements. A modest increase in risk was observed for vitamin $\mathrm{E}$ and a nearly threefold increase in risk for vitamin A, although the number of women reporting use of this supplement was very small. Among white women, any use of multivitamins, vitamin $\mathrm{C}$ or vitamin $\mathrm{E}$ was each associated with a $20-25 \%$ reduction in breast cancer risk, although the confidence intervals around all of these point estimates included one. Analyses examining duration of use did not show clear dose-response relationships. Risk was elevated for short-term users, and the reduction in risk was similar for women reporting 1 to 3 years of use and greater than 3 years of use. It should be noted that some of the categories of vitamin use had relatively few women in them, and confidence intervals around estimates for black women and white women overlapped considerably.

Most women who were vitamin users reported taking more than one type of vitamin. Among women reporting multivitamin use, nearly three-quarters of them also reported use of additional individual supplements. Conversely, over $80 \%$ of the women reporting use of vitamin $\mathrm{A}, \mathrm{C}$ or $\mathrm{E}$ as individual supplement also reported taking multivitamins. To take into account that relatively few women used only a single supplement, we constructed multivariate models that controlled for other vitamin use. The results of these models are presented in Table 4. Adjusting for other vitamin use had modest effects on most of the ORs. Among black women, there was still no evidence of inverse associations with any of the vitamin supplements. Among white women, the modest inverse associations observed for multivitamins, vitamin $\mathrm{C}$ and vitamin $\mathrm{E}$ were attenuated when adjusting for other vitamin use. There were non-significant elevations in the ORs associated with use of vitamin A or $\beta$-carotene when adjusting for other vitamin use.

We also examined whether the relationship between vitamin supplement intake and breast cancer was 
Table 3 Odds ratios (ORs) for breast cancer associated with vitamin supplement use, among black women and white women, The Carolina Breast Cancer Study

\begin{tabular}{|c|c|c|c|c|c|c|c|c|c|c|c|c|}
\hline & \multicolumn{4}{|c|}{ All women } & \multicolumn{4}{|c|}{ Black women } & \multicolumn{4}{|c|}{ White women } \\
\hline & Cases & Controls & $\mathrm{OR}^{*}$ & $95 \% \mathrm{Cl}$ & Cases & Controls & $\mathrm{OR}^{*}$ & $95 \% \mathrm{Cl}$ & Cases & Controls & $\mathrm{OR}^{*}$ & $95 \% \mathrm{Cl}$ \\
\hline No vitamin use & 385 & 339 & 1.00 & & 183 & 178 & 1.00 & & 202 & 161 & 1.00 & \\
\hline Any vitamin use & 476 & 451 & 0.85 & $(0.68-1.07)$ & 152 & 154 & 0.95 & $(0.66-1.38)$ & 324 & 297 & 0.80 & $(0.59-1.09)$ \\
\hline \multicolumn{13}{|l|}{ Multivitamins } \\
\hline Any use & 410 & 369 & 0.89 & $(0.70-1.13)$ & 136 & 129 & 1.04 & $(0.71-1.52)$ & 274 & 240 & 0.81 & $(0.59-1.12)$ \\
\hline$<1$ year of use & 103 & 66 & 1.45 & $(0.98-2.14)$ & 43 & 24 & 2.22 & $(1.16-4.25)$ & 60 & 42 & 1.19 & $(0.72-1.96)$ \\
\hline 1 to 3 years of use & 166 & 183 & 0.73 & $(0.54-0.98)$ & 59 & 72 & 0.79 & $(0.49-1.27)$ & 107 & 111 & 0.71 & $(0.48-1.05)$ \\
\hline$>3$ years of use & 141 & 120 & 0.83 & $(0.59-1.17)$ & 34 & 33 & 0.87 & $(0.47-1.60)$ & 107 & 87 & 0.76 & $(0.50-1.15)$ \\
\hline \multicolumn{13}{|l|}{ Vitamin C } \\
\hline Any use & 196 & 188 & 0.87 & $(0.64-1.18)$ & 50 & 50 & 1.10 & $(0.63-1.91)$ & 146 & 138 & 0.78 & $(0.54-1.14)$ \\
\hline$<1$ year of use & 64 & 49 & 1.06 & $(0.66-1.71)$ & 16 & 19 & 0.79 & $(0.32-1.92)$ & 48 & 30 & 1.23 & $(0.69-2.22)$ \\
\hline 1 to 3 years of use & 78 & 89 & 0.71 & $(0.48-1.05)$ & 24 & 25 & 1.07 & $(0.52-2.22)$ & 54 & 64 & 0.56 & $(0.34-0.92)$ \\
\hline$>3$ years of use & 54 & 50 & 1.00 & $(0.62-1.62)$ & 10 & 6 & 2.21 & $(0.65-7.50)$ & 44 & 44 & 0.80 & $(0.47-1.39)$ \\
\hline \multicolumn{13}{|l|}{ Vitamin E } \\
\hline Any use & 153 & 147 & 0.92 & $(0.67-1.28)$ & 49 & 41 & 1.32 & $(0.75-2.33)$ & 104 & 106 & 0.75 & $(0.49-1.13)$ \\
\hline$<1$ year of use & 59 & 33 & 1.54 & $(0.91-2.59)$ & 23 & 17 & 1.20 & $(0.54-2.66)$ & 36 & 16 & 1.82 & $(0.88-3.76)$ \\
\hline 1 to 3 years of use & 54 & 70 & 0.71 & $(0.45-1.10)$ & 16 & 16 & 1.41 & $(0.60-3.35)$ & 38 & 54 & 0.51 & $(0.29-0.87)$ \\
\hline$>3$ years of use & 40 & 44 & 0.78 & $(0.46-1.35)$ & 10 & 8 & 1.45 & $(0.47-4.47)$ & 30 & 36 & 0.63 & $(0.34-1.20)$ \\
\hline \multicolumn{13}{|l|}{ Vitamin A } \\
\hline Any use & 40 & 26 & 1.59 & $(0.87-2.89)$ & 17 & 6 & 2.84 & $(0.98-8.22)$ & 23 & 20 & 1.12 & $(0.51-2.46)$ \\
\hline \multicolumn{13}{|l|}{$\beta$-carotene } \\
\hline Any use & 33 & 32 & 1.36 & $(0.74-2.49)$ & 7 & 6 & 1.13 & $(0.28-4.60)$ & 27 & 26 & 1.28 & $(0.63-2.61)$ \\
\hline \multicolumn{13}{|l|}{ Selenium } \\
\hline Any use & 15 & 12 & 1.34 & $(0.56-3.20)$ & 2 & 1 & - & - & 13 & 12 & 1.16 & $(0.45-2.94)$ \\
\hline
\end{tabular}

${ }^{*}$ Adjusted for age, age at menarche, age at first full-term pregnancy, menopausal status, lactation history, family history, BMI, WHR, education, alcohol use, smoking history, and fruit and vegetable intake.

modified by either dietary intake of fruit and vegetables or alcohol consumption, since previous reports have suggested a stronger protective effect of vitamin supplements among women who had low dietary intake of vitamins or higher alcohol consumption ${ }^{9,23}$. There were no consistent patterns of smaller ORs for vitamin supplement intake among women with a low fruit and vegetable intake $(\leq 20$ servings per week) as compared to those with a higher intake. Among white women, the ORs (and 95\% CIs) for multivitamin use were $0.93(0.55-1.59), 0.64(0.35-1.20)$ and $0.85(0.46-1.58)$ for women with low, medium and high fruit and vegetable intake, respectively. For black women, the corresponding ORs (and 95\% CIs) were 0.99 (0.51-1.93), $0.81(0.35-1.87)$ and $0.86(0.43-1.74)$. We also did not observe stronger inverse associations among women who reported alcohol consumption (data not shown). Because there were so few moderate to heavy drinkers in this population, alcohol consumption was dichotomised into ever or never drinkers for these analyses.

\section{Discussion}

In this case-control study of North Carolina women, we found only very limited support for the hypothesis that

Table 4 Odds ratios (ORs) for breast cancer associated with vitamin supplement use, adjusted for use of other supplements, among black women and white women, The Carolina Breast Cancer Study

\begin{tabular}{|c|c|c|c|c|c|c|}
\hline & \multicolumn{2}{|c|}{ All women } & \multicolumn{2}{|c|}{ Black women } & \multicolumn{2}{|c|}{ White women } \\
\hline & $\mathrm{OR}^{*}$ & $95 \% \mathrm{Cl}$ & $\mathrm{OR}^{*}$ & $95 \% \mathrm{Cl}$ & $\mathrm{OR}^{*}$ & $95 \% \mathrm{Cl}$ \\
\hline Any multivitamin use & 0.95 & $(0.74-1.20)$ & 1.04 & $(0.74-1.56)$ & 0.91 & $(0.67-1.25)$ \\
\hline Any use of vitamin C & 0.88 & (0.64-1.19) & 0.92 & $(0.51-1.67)$ & 0.85 & $(0.59-1.24)$ \\
\hline Any use of vitamin $E$ & 0.95 & $(0.68-1.32)$ & 1.12 & $(0.60-2.10)$ & 0.85 & $(0.57-1.28)$ \\
\hline Any use of vitamin A & 1.86 & $(1.00-3.48)$ & 2.65 & $(0.83-8.40)$ & 1.49 & $(0.68-3.25)$ \\
\hline Any use of $\beta$-carotene & 1.37 & $(0.72-2.60)$ & 0.93 & $(0.23-3.68)$ & 1.62 & $(0.78-3.38)$ \\
\hline Any use of selenium & 0.97 & $(0.38-2.49)$ & - & - & 1.11 & $(0.41-3.07)$ \\
\hline
\end{tabular}

* ORs adjusted for age, age at menarche, age at first full-term pregnancy, menopausal status, lactation history, family history, BMI, WHR, education, alcohol use, smoking history, fruit and vegetable intake, and each of the other vitamins. 
vitamin supplement use is associated with a decreased risk of breast cancer. Among white women, any use of multivitamins, vitamin $\mathrm{C}$ or vitamin $\mathrm{E}$ in the past five years was each associated with an approximately $20 \%$ decrease in breast cancer risk; however, the confidence intervals around these estimates all included one. There was no evidence of a dose-response relationship between duration of use and breast cancer risk. In contrast to the modest inverse associations with certain vitamin supplements suggested for white women, there was essentially no evidence of a protective effect among black women for any of the vitamins examined.

There is no clear reason why the effects of vitamin supplements might be different in black women than in white women. Among the studies examining breast cancer risk factors for blacks ${ }^{14-19}$, none has examined vitamin supplementation or dietary factors so there are no other studies to which these results can be compared. One might speculate that there were racial differences in vitamin intake through dietary sources and, as has been reported in one study, that the adequacy of dietary intake influences whether supplementation has a protective effect ${ }^{9}$.

Although complete diet histories were not taken, the information obtained regarding average weekly servings of fruit and vegetables suggested that there were not substantial racial differences. The mean number of servings of fruit and vegetables per week among white controls and black controls was 27 and 29, respectively. These averages were quite similar to the fruit and vegetable consumption reported in another study of African-American women in North Carolina (3.93 per day or 27.5 per week) which used a more detailed foodfrequency questionnaire ${ }^{24}$. While the dietary data have obvious limitations, they are concordant with data from a national survey, suggesting that fruit and vegetable consumption does not vary substantially between blacks and whites ${ }^{25,26}$.

The findings suggesting increased breast cancer risk among women reporting vitamin A or $\beta$-carotene use were unexpected and should be interpreted cautiously given the small number of women reporting use of these supplements. Nonetheless, recent laboratory and epidemiological studies provide evidence that would tend to support these observations. Increased cancer risk was observed in two randomised controlled trials of $\beta$ carotene, and laboratory studies have suggested mechanisms for both procarcinogenic and anticarcinogenic effects $^{27,28}$.

When interpreting the results of this study, one must consider the possibility that vitamin supplement use is a marker for a healthy lifestyle. Our study and others ${ }^{29,30}$ have shown that individuals who take vitamin supplements tend to have characteristics that are typically associated with lower risk of chronic diseases, including cancer. As compared with women in our population who reported no use of vitamins, vitamin users were more highly educated, had a lower BMI and WHR, consumed more fruit and vegetables, and were more likely to engage regularly in fitness activities. Although we attempted to control for the effects of these factors in our multivariate models, it is possible that there was residual confounding, and the modest reduction in breast cancer risk observed for certain types of vitamin use reflects their association with a healthy lifestyle.

The limitations of the study should be acknowledged. Vitamin supplement intake was based on self-reported use over the past five years. Inaccurate recall or the restriction of the questions to use over the past five years rather than a longer period may have resulted in misclassification of exposure. Since the questionnaire was administered in a standardised fashion by trained interviewers, it seems likely that this misclassification would have been non-differential between cases and controls, resulting in attenuation of the ORs. If recall was differential by case status, and cases were more likely than controls to recall vitamin use, any protective effects of vitamins would have been underestimated.

Data regarding dietary intake of vitamins were clearly limited. It should be kept in mind, however, that the goal of this study was to estimate the effects of vitamin supplements, not the effects of vitamins from all sources. We did attempt to control for dietary intake by including a term for the number of servings of fruit and vegetables consumed each week in the multivariate models, and by performing analyses stratified by categories of fruit and vegetable intake. The relationships with supplement use did not vary substantially when taking dietary intake into account. Nonetheless, if the effects of vitamin supplements are strongly dependent on the sufficiency of dietary intake, our adjustment for fruit and vegetable intake may have been inadequate.

Overall, the results of this study support the bulk of the epidemiological evidence, which suggests that vitamin supplements do not substantially reduce the risk of breast cancer $^{6}$. While there is compelling evidence that dietary factors are likely an important determinant of cancer risk $^{31}$, reductions in risk most likely will be achieved through modification of overall dietary patterns rather than by supplementation with one or more micronutrients. Additional research is needed to clarify the role of nutritional factors in breast cancer, particularly among black women.

\section{Acknowledgements}

This work was supported by a FIRST award (R29CA67385) to PGM and a Specialized Program of Research Excellence (SPORE) in breast cancer grant (P50CA58223), both funded by the National Cancer Institute. The authors wish to thank the CBCS nurse-interviewers: Carolyn Dunmore, Dianne Mattingly, Theresa Nalevaiko, 
Patricia Plummer and Cheryl Robinson. We also thank Dr Bette Caan for her help in developing dietary questions and Dr Susan Mayne for her helpful suggestions on analysing the data.

\section{References}

1 Dorgan JF, Schatzkin A. Antioxidant micronutrients in cancer prevention. Nutr. Cancer 1991; 5: 43-68.

2 Machlin LJ, Bendich A. Free radical tissue damage: protective role of antioxidant nutrients. FASEB J. 1987; 1: 441-5.

3 Blomhoff R. Overview of vitamin A metabolism and function. In: Blumhoff R, ed. Vitamin A in Health and Disease. New York, NY: Marcel Dekker, 1994; 1-35.

4 Mirvish SS. Effects of vitamins $\mathrm{C}$ and $\mathrm{E}$ on $\mathrm{N}$-nitroso compound formation, carcinogenesis, and cancer. Cancer 1986; 58: 1842-50

5 Kelley DS, Bendich A. Essential nutrients and immunologic functions. Am. J. Clin. Nutr. 1996; 63: 994S-6S.

6 Patterson RE, White E, Kristal AR, Neuhouser ML, Potter JD. Vitamin supplements and cancer risk: the epidemiologic evidence. Cancer Causes Control 1997; 8: 786-802.

7 Garland M, Willett WC, Manson JE, Hunter DJ. Antioxidant micronutrients and breast cancer. J. Am. Coll. Nutr. 1993; 12: 400-11.

8 Hunter DJ, Willett WC. Diet, body size, and breast cancer. Epidemiol. Rev. 1993; 15: 110-32.

9 Hunter DJ, Manson JE, Colditz GA, Stampfer MJ, Rosner B, Hennekens CH, Speizer FE, Willett WC. A prospective study of the intake of vitamins $\mathrm{C}, \mathrm{E}$, and $\mathrm{A}$ and the risk of breast cancer. N. Engl. J. Med. 1993; 329: 234-40.

10 Rohan TE, Howe GR, Friedenreich CM, Jain M, Miller AB Dietary fiber, vitamins $\mathrm{A}, \mathrm{C}$, and $\mathrm{E}$, and risk of breast cancer: a cohort study. Cancer Causes Control 1993; 4: 29-37.

11 Kushi LH, Fee RM, Sellers TA, Zheng W, Folsom AR. Intake of vitamins A, C, E and postmenopausal breast cancer. Am.J. Epidemiol. 1996; 144: 165-74.

12 Slesinski MJ, Subar AF, Kahle LL. Trends in use of vitamin and mineral supplements in the U.S. J. Am. Diet. Assoc. 1995; 95: 921-3.

13 U.S. Food and Drug Administration, Center for Food Safety and Applied Nutrition. Economic Characterization of the Dietary Supplement Industry Final Report [Online]. Available at http://vm.dfsan.fda.gov/ comm. March 1999.

14 Mayberry RM. Age-specific patterns of association between breast cancer and risk factors in black women, ages 20 to 39 and 40 to 54. Ann. Epidemiol. 1994; 4: 205-13.

15 Mayberry RM, Stoddard-Wright C. Breast cancer risk factors among black women and white women: similarities and differences. Am. J. Epidemiol. 1992; 136: 1445-56.

16 Austin H, Cole P, Wynder E. Breast cancer in black American women. Int. J. Cancer 1979; 24: 541-4.

17 Schatzkin A, Palmer JR, Rosenberg L, Helmrich SP, Miller DR, Kaufman DW, Lesko SM, Shapiro S. Risk factors for breast cancer in black women. J. Natl. Cancer Inst. 1987; 78: 213-7.

18 Brinton LA, Benichou J, Gammon MD, Brogan DR, Coates R, Schoenberg JB. Ethnicity and variation in breast cancer incidence. Int. I. Cancer 1997; 73: 349-55.

19 Palmer JR, Rosenberg L, Rao RS, Strom BL, Warshauer ME, Harlap S, Zauber A, Shapiro S. Oral contraceptive use and breast cancer risk among African-American women. Cancer Causes Control 1995; 6: 321-31.

20 Newman B, Moorman PG, Millikan R, et al. The Carolina Breast Cancer Study: integrating population-based epidemiology and molecular biology. Breast Cancer Res. Treatment 1995; 35: 51-60.

21 Weinberg CR, Sandler DP. Randomized recruitment in casecontrol studies. Am. J. Epidemiol. 1991; 134: 421-32.

22 Moorman PG, Newman B, Millikan RC, Tse C-KJ, Sandler DP. Participation rates in a case-control study: the impact of age, race, and race of interviewer. Ann. Epidemiol. 1999; 9: 18895.

23 Zhang S, Hunter DJ, Hankinson SE, et al. A prospective study of folate intake and the risk of breast cancer. JAMA 1999; 281: 1632-7.

24 McClelland JW, Demark-Wahnefried W, Mustian RD, Cowan AT, Campbell MK. Fruit and vegetable consumption of rural African Americans: baseline survey results of the Black Churches United for Better Health 5 a day project. Nutr. Cancer 1998; 30: 148-57.

25 Popkin BM, Siega-Riz AM, Haines PS. A comparison of dietary trends among racial and socioeconomic groups in the United States. N. Engl. J. Med. 1996; 335: 716-20.

26 Popkin BM, Siega-Riz AM, Haines PS. Correction and revision of conclusions - dietary trends in the United States. N. Engl. J. Med. 1997; 337: 1846-8.

27 Pryor WA, Stahl W, Rock CL. Beta carotene: from biochemistry to clinical trials. Nutr. Rev. 2000; 58: 39-53.

28 Wang X-D, Russell RM. Procarcinogenic and anticarcinogenic effects of $\beta$-carotene. Nutr. Rev. 1999; 57: 263-72.

29 Slesinski MJ, Subar AF, Kahle LL. Dietary intake of fat, fiber and other nutrients is related to the use of vitamin and mineral supplements in the United States: the 1992 National Health Interview Survey. J. Nutr. 1996; 126: 3001-8.

30 Patterson RE, Neuhouser ML, White E, Hunt JR, Kristal AR. Cancer-related behavior of vitamin supplement users. Cancer Epidemiol. Biomark. Prev. 1998; 7: 79-81.

31 DeMarini DM. Dietary interventions of human carcinogenesis. Mutation Res. 1998; 457-65. 